\title{
Terapia Ocupacional Social na assistência ao idoso: história de vida e produção de significados
}

\author{
Amabile Teresa de Lima Neves, Maria Daniela Corrêa de Macedo \\ Departamento de Terapia Ocupacional, Universidade Federal do Espírito Santo - UFES, Vitória, ES, Brasil.
}

\begin{abstract}
Resumo: Este artigo trata do relato da experiência do acompanhamento de uma idosa pelo Serviço Especializado de Assistência Domiciliar - SEAD pertencente à rede socioassistencial do município de Vitória, ES. Por meio do Centro de Referência Especializado da Assistência Social - CREAS, o SEAD é ofertado a pessoas com deficiência e idosos com algum grau de dependência e em situação de violações de direitos, bem como para seus cuidadores e familiares. No intento de contextualizar a experiência pretende-se explicitar o SEAD e suas particularidades, tanto no que diz respeito ao Serviço Único de Assistência Social - SUAS e à Política Nacional de Assistência Social - PNAS quanto em relação ao Estado do Espírito Santo, pioneiro em sua implantação em nível nacional. Será aprofundado ainda o debate acerca do papel da terapia ocupacional nesse serviço, no propósito de abordar e discutir as metodologias e intervenções realizadas por essa área profissional no estudo de caso, vindo a acrescer ao corpo de estudos dedicados à terapia ocupacional social.
\end{abstract}

Palavras-chave: Idoso, Vulnerabilidade Social, Terapia Ocupacional, Assistência Social.

\section{Social Occupational Therapy in the care of the elderly: life history and production of meanings}

\begin{abstract}
This paper addresses the experience report of accompanying an elderly woman attended by the Specialized Home Care Service (SEAD) of the social assistance network of the municipality of Vitoria, Espirito Santo state, Brazil. Through the Social Assistance Specialized Reference Center (CREAS), SEAD is offered to people with disabilities and older people with some degree of dependency and under situation of violation of human rights, as well as to their caregivers and family. In order to contextualize the experience, we intend to explain this specialized service and its particularities with regard to the General Social Assistance Service (SUAS), the National Social Assistance Policy (PNAS), and the state of Espirito Santo - pioneer in its implementation at national level. Also, the debate on the role of Occupational Therapy in this service will be studied more comprehensively in an attempt to address and discuss the methodologies and interventions used by this professional area in this case study, contributing to the literature dedicated to Social Occupational Therapy.
\end{abstract}

Keywords: Aged, Social Vulnerability, Occupational Therapy, Social Assistance.

\section{Introdução}

O cotidiano, palco onde a vida acontece, é constituído por meio da imbricação das relaçóes e açôes humanas. É onde o individual e o coletivo tencionam seu diálogo numa busca por satisfazer as necessidades de ambas as partes, e nessa busca a cultura, as representaçôes, as práticas sociais e as histórias de vida são construídas num tempo-espaço e contexto sociopolítico próprios. Dessa forma, na vida cotidiana o homem vai exercer sua ação transformadora num movimento de constante negociação entre

Autor para correspondência: Amabile Teresa de Lima Neves, Departamento de Terapia Ocupacional, Universidade Federal do Espírito Santo, Av. Marechal Campos, 1468, Maruípe, CEP 29040-090, Vitória, ES, Brasil, e-mail: mabi_tln@yahoo.com.br

Recebido em Ago. 31, 2014; $1^{\text {a }}$ Revisão em Nov. 3, 2014; Aceito em Fev. 6, 2015. 
a realidade interna (a sua realidade) e a realidade externa (a realidade do coletivo e do contexto no qual o sujeito está inserido) (GALHEIGO, 2003).

Por meio desse cenário de trocas e dialética, repleto de açôes humanas e atores que as compóem e as escrevem, as atividades humanas ganham sentido e tornam-se significativas (BARROS; GHIRARDI; LOPES, 2002). Todavia, nem sempre o diálogo entre o indivíduo e o coletivo/contexto consegue ser estabelecido as práticas transformadoras serem exercidas, por conseguinte ocorrerão rupturas no cotidiano dos sujeitos e/ou grupos levando o homem a ficar vulnerável, quando não em risco pessoal, social e em profundo rompimento com a sociedade pertencente (CASTEL, 1993). Nesse sentido, as sociedades têm buscado formas de enfrentamento às problemáticas sociais para que indivíduos e grupos em vulnerabilidade possam sair dessa zona de fragilidade e exercerem a autonomia da própria vida, voltando a dialogarem com o meio do qual fazem parte e a imprimirem sua marca emancipatória neste.

Imerso nesse contexto, este artigo foi desenhado na intençáo de apresentar o relato da experiência do acompanhamento de um caso pelo Serviço Especializado de Assistência Domiciliar - SEAD para pessoas com deficiência e idosos com algum grau de dependência e em situação de violaçôes de direitos, como também para seus cuidadores e familiares. Esse serviço faz parte da rede socioassistencial do município de Vitória, ES, e é ofertado pelo Centro de Referência Especializado da Assistência Social - CREAS, que dispõe de três unidades de referência até o presente momento. A experiência discorrida a seguir se deu no SEAD pertencente à unidade do CREAS-Maruípe.

Pretende-se explicitar o SEAD (suas particularidades) e o contexto em que está inserido dentro do SUAS e da Política Nacional de Assistência Social (PNAS), para posteriormente aprofundar o papel da terapia ocupacional enquanto profissão que compóe o corpo técnico desse serviço, partindo para o relato do caso na intenção de abordar e discutir as metodologias e intervenções realizadas pelo terapeuta ocupacional nessa experiência, vindo a acrescer ao corpo de estudos dedicados à terapia ocupacional social.

\section{O Serviço de Atendimento Domiciliar - SEAD na}

\section{Assistência Social de Vitória, ES}

Em 11 de novembro de 2009, a Resolução CNAS n. 109, aprovou a Tipificação Nacional dos Serviços Socioassistenciais, a qual organiza os serviços por níveis de complexidade do SUAS (Sistema Único da Assistência Social) em: Proteção Social Básica e
Proteção Social Especial de Média e Alta Complexidade, visando atender os usuários da Política Nacional de Assistência Social (PNAS) - indivíduos e famílias com fragilidades e/ou rupturas nas relaçóes sociais, nas redes de trabalho formal e informal, envolvidos em diferentes formas de violência e violação de direitos - com o objetivo de apoio, orientação e acompanhamento direcionados para promoção de direitos, preservaçáo e fortalecimento de vínculos familiares, comunitários e sociais e para o fortalecimento da função protetiva das redes sociofamiliares de suporte (BRASIL, 2009).

No intento de ir ao encontro das demandas peculiares de seus usuários, a Secretaria de Assistência Social do município de Vitória, ES, instituiu no ano de 2012, pioneiramente em nível nacional, o Serviço Especializado de Atendimento Domiciliar - SEAD para pessoas com deficiência e idosos com algum grau de dependência e em situação de violaçóes de direitos, como também para seus cuidadores e familiares. A justificativa para sua criação se deu por meio da constataçáo, pelo Manual do Conselho Municipal do Idoso de Vitória - COMID (CONSELHO..., 2010b), de que a partir da década de 1980 houve um crescimento significativo da população idosa (indivíduos com idade acima dos 60 anos) e um aumento relativamente proporcional da ocorrência de doenças crônico-degenerativas, que tornaram a incapacidade funcional mais presente nos idosos. Este quadro clínico consequentemente leva à falta de independência que se constitui em um fator de alto risco para ocorrência de maus-tratos e violação de direitos, não pela dependência em si, mas porque a família e/ou a comunidade das quais idosos e pessoas com deficiência fazem parte nem sempre estâo preparadas para lidar com a situação, seja devido ao despreparo emocional, relacional e técnico, seja por falta de condições socioeconômicas. Ademais, a dificuldade em lidar com as mudanças abruptas do cotidiano familiar e a sobrecarga dos cuidadores igualmente agravam a situação de violações de direitos, resultando que o maior índice de agressores seja constituído pelos cuidadores das próprias vítimas - frequentemente parentes próximos (BRASIL, 2002).

Embora a tipificação regulamente a organização dos serviços socioassistenciais, a estruturação e composição destes não são rígidas e dependerão das particularidades locais e regionais, do território e das necessidades dos usuários. Desse modo, o SEAD é ofertado pelo CREAS que compóe a rede de Serviços de Proteção Social Especial de Média Complexidade, uma vez que esse nível de proteção compreende a atenção à situação de ameaça ou a 
violação de direitos já instalados (violência física, psicológica, sexual, econômica, tráfico de pessoas, cumprimento de medidas socioeducativas em meio aberto e protetivas).

\subsection{A Terapia Ocupacional e o SEAD}

O SEAD é composto por uma equipe multiprofissional formada pelo assistente social, psicólogo e terapeuta ocupacional. Para essa composição considerou-se a diversidade de problemáticas que o Serviço de Proteção Social Especial às pessoas com deficiência e idosas e suas famílias na média complexidade poderiam vir a trabalhar:

[...] famílias com pessoas com deficiência e idosos com algum grau de dependência, que tiveram suas limitaçôes agravadas por violaçóes de direitos tais como: exploração da imagem, isolamento, confinamento, atitudes discriminatórias e preconceituosas no seio da família, falta de cuidados adequados por parte do cuidador, alto grau de estresse do cuidador, desvalorização da potencialidade/capacidade da pessoa dentre outras que agravam a dependência e comprometem o desenvolvimento da autonomia (BRASIL, 2009, p. 26).

Na prática, a equipe SEAD funciona com duplas de profissionais, contando cada profissional com um estagiário correspondente à sua área. No município de Vitória há três CREAS, divididos de acordo com as regiôes e territórios socioassistenciais, cada um possui um SEAD, com os técnicos dispostos da seguinte maneira: SEAD/CREAS-Centro: terapeuta ocupacional e assistente social; SEAD/CREAS-Bento Ferreira: psicólogo e assistente social; SEAD/CREAS-Maruípe: terapeuta ocupacional e assistente social.

A presença do terapeuta ocupacional no SEAD foi legitimada pelo reconhecimento da complexidade das situaçôes enfrentadas em consonância com a Resolução CNAS no 17, de junho de 2011, que compreende a necessidade de outras categorias profissionais de nível superior, dentre elas o terapeuta ocupacional, para atender às especificidades dos serviços socioassistenciais (BRASIL, 2011). Todavia, é pertinente ressaltar que a terapia ocupacional no SUAS se faz presente também por causa do contexto histórico de lutas internas e externas da profissão, que culminaram para que os objetivos gerais de trabalho desta categoria, bem como suas estratégias e tecnologias, se articulassem coerentemente às diretrizes do SUAS bem como às singularidades dos Serviços Socioassistenciais (ALMEIDA et al., 2012; CONSELHO..., 2010a).
No campo social a terapia ocupacional trabalha com indivíduos e grupos em vulnerabilidade social, em que há a fragilidade dos vínculos relacionais e a precariedade dos processos de trabalho; e/ou que já se encontram desfiliados, em ruptura total com as redes de trabalho e com as redes pessoais e sociais de suporte e participação (CASTEL, 1993).

Através do uso das atividades como instrumento de mediação sócio-ocupacional, o terapeuta ocupacional busca junto com os sujeitos elou coletivos ${ }^{1}$ mediar às relações visando o diálogo entre o sujeito e seu grupo, sua historicidade e seu contexto cultural a fim de que novos (re)arranjos e (re)significados para o seu cotidiano e sua história de vida sejam encontrados, novas redes formadas e outras fortalecidas, de modo que o sujeito possa (re)construir seu protagonismo, autonomia e independência, sendo capaz de estar e circular pela vida num processo contínuo de emancipação (BARROS; GHIRARDI; LOPES, 2002).

Para tais açôes o terapeuta ocupacional social se utilizará de metodologias próprias, de acordo com recorte teórico metodológico da terapia ocupacional social, como: (re)construção de projetos de vida e mediação de conflitos (BARROS; GHIRARDI; LOPES, 2002), intervenção coletiva (BARROS; LOPES; GALHEIGO, 2007b), história oral de vida, negociação cultural e intergeracional (COSTA, 2008; COSTA; ALVARENGA; ALVARENGA, 2007), oficinas sócio-ocupacionais (LOPES et al., 2011), acompanhamento individual e territorial (LOPES; BORBA; CAPELLARO, 2011).

\section{O SEAD-Maruípe, a Terapia Ocupacional Social e o caso de uma usuária: encontros e diálogos com uma história de vida}

\subsection{Os primeiros encontros: conhecendo parte da história de vida de uma idosa}

Em 21/3/2013 um relatório de denúncia do Disque 100 foi encaminhado à equipe do SEAD/CREAS-Maruípe afirmando que a sra. D., 67 anos, moradora do bairro Maruípe, estava agredindo física e psicologicamente o marido idoso e acamado. A denúncia havia sido feita pelos enteados da idosa que não residiam com ela. Para que pudesse responder ao relatório a equipe SEAD programou uma visita domiciliar com o propósito de conhecer a real situação familiar, assim como entrou 
em contato telefônico com os filhos do idoso para ouvi-los. A fala comum a todos os filhos apontava a sra. D. como o cerne do problema. Ela não aceitava que a ajudassem nos cuidados com o marido e não gostava de visitas no domicílio, os tratando mal com palavras agressivas e de baixo caláo.

Ao chegar no domicílio a própria sra. D. atendeu à equipe SEAD. Com olhos cor de jabuticaba bastante expressivos, cabelos brancos como algodáo e dona de uma estatura delicada, a sra. D. não parecia feliz com a presença do SEAD. Quando a equipe se apresentou a idosa inflamou-se afirmando que sabia quem havia pedido a presença do serviço ali (referindo-se aos enteados). Declarou que os enteados queriam fiscalizar a forma como ela cuidava do marido, logo o SEAD estava ali para igualmente fiscalizá-la. "Podem entrar na casa e observar tudo, minha consciência está tranquila quanto aos cuidados do meu marido" (sic sra. D.). Era notório o processo de esgotamento da sra. D., à medida que falava seu tom de voz se elevava e o cansaço transparecia em seu rosto.

Além do marido acamado a sra. D. ainda cuidava de sua mãe também idosa e cadeirante, que devido sua condição demandava ajuda nos cuidados básicos. Não possuía filhos e contava somente com a ajuda de seus irmãos, porém estes nem sempre estavam disponíveis. As profissionais explicaram que o objetivo do serviço não era fiscalizar as famílias, contrariamente, era acompanhá-las e assisti-las ofertando apoio e suporte tanto aos idosos e/ou deficientes quanto aos seus cuidadores e familiares. A sra. D. disse que estava cansada das pessoas oferecerem ajuda e sumirem, que assim havia acontecido com os enteados quando o marido estava no hospital, após ter sofrido o acidente vascular encefálico. Todos disseram que ajudariam nos cuidados, chegando a criar uma tabela de revezamento que fora seguida somente na primeira semana do idoso em casa. Depois passaram a visitá-lo raramente, e quando apareciam era na hora que queriam, não respeitavam as normas da casa e nem os horários do pai. Chegavam levantando os lençóis do leito e perguntando acusatoriamente sobre as escaras em processo de cicatrização e outras manchas aparecidas no corpo do idoso. Toda essa movimentação e a forma como os enteados agiam a aborreciam e a faziam se sentir desqualificada e invadida.

Diante do contexto a equipe SEAD identificara um conflito familiar e, embora a violação de direitos não estivesse instalada para com o idoso, percebera os vínculos bastante fragilizados a ponto de desencadear episódios de violência, fosse com o idoso e/ou entre a sra. D. e seus enteados. Logo, as técnicas propuseram à sra. D. o acompanhamento sistemático à família para a mediaçáo e resolubilidade do conflito. A idosa aceitou mesmo bastante descrente do propósito do serviço.

\subsection{O recorte teórico-metodológico em Terapia Ocupacional Social e a vivência das intervenções: conhecendo a fundo a história de vida da sra. $D$.}

As visitas à sra. D. tornaram-se semanais. A princípio a terapeuta ocupacional propôs trabalhar com a memória social da idosa, na intenção de que o vínculo se estreitasse e a sra. D. pudesse iniciar o processo de retomar o protagonismo de sua vida ao ver-se além da sobrecarga, agressividade e irritabilidade, características sobressalentes nos primeiros contatos.

A história de vida da sra. D. começou a ser conhecida durante os cafés da tarde que ela oferecia à equipe SEAD. Era uma história repleta de autonomia, independência e emancipação. A idosa foi costureira de famílias abastadas nos tempos em que a profissão era valorizada e bastante requisitada, conhecida como "alta costura". Devido ao seu trabalho vivia viajando e conhecendo novos lugares. Tinha uma posiçáo privilegiada dentro das casas de família, tratada para além do vínculo empregatício, como parte integrante do núcleo familiar, chegando a costurar para várias geraçôes de uma mesma família. Como fruto do seu trabalho comprou uma casa para si e ajudou na situação financeira de seus pais. Nunca dependeu de outrem para se manter, o que a levou a se casar tardiamente com o sr. A., com quem permanece em uniáo até os dias atuais.

De acordo com a sra. D., casou-se por gostar do sr. A. e por ver nele um grande companheiro, uma vez que este era viúvo e já tinha os filhos casados. Contou que pelo fato de também náo ter filhos os dois moravam sozinhos, porém auxiliavam os filhos do sr. A., principalmente financeiramente. A idosa considerava que a relação entre eles era harmoniosa, não de encontros frequentes, mas nas datas festivas se reuniam, por isso não esperava o desrespeito dos enteados.

Sempre emocionada ao falar da família, dizia que nunca cogitara maltratar o marido, pois os dois sempre viveram muito bem. Todavia, estava cansada, sentia dores e tensóes musculares, dormia pouco, estava emagrecendo devido ao novo rearranjo do cotidiano, não tinha tempo pra si e ainda se sentia 
injustiçada e desgastada pelas acusaçóes. Todos esses agravantes a levavam a perder a vontade de viver.

A sra. D. via-se apenas como a cuidadora de um homem adoecido que mal falava e que estava com as funções cognitivas precárias devido às sequelas do acidente vascular encefálico, o que proporcionava ao sr. A. falas desconexas, delírios, o ciclo do sono desregulado e a demanda de cuidados especiais diários.

À medida que a equipe oferecia a escuta à idosa sem repreendê-la ou julgá-la o vínculo foi sendo estabelecido. Conhecer a história de vida da sra. D. foi crucial para o estreitamento da relação e para a equipe traçar as próximas intervençôes. Conforme discorrem Barros, Lopes e Galheigo (2007a, p. 352), é pertinente que o terapeuta ocupacional no campo social conheça os sujeitos e grupos sociais a quem acompanha, "[...] como vivem, onde moram, como constroem as relaçôes familiares, os laços de amizade e os desejos", pois assim o profissional pode se conscientizar da realidade em que se encontra, imergindo-se nela para seguidamente distanciar-se, movimento esse que lhe possibilita compreender as razóes das situaçōes conflituosas e gerar a "ação transformadora dessa realidade". Para a terapeuta ocupacional do SEAD esse saber auxiliou na escolha das metodologias que a levassem a alcançar o objetivo de buscar junto com a sra. D. o (re)arranjo do cotidiano dela, a produção de novos potenciais e novos sentidos para a sua história, e o fortalecimento das suas redes sociais de suporte. Nessa perspectiva, a terapeuta ocupacional e a estagiária de terapia ocupacional escolheram por metodologia de intervenção Acompanhamento Individual e Territorial.

Compreendendo que Acompanhamento Individual e Territorial em Terapia Ocupacional Social ultrapassa o "[...] aspecto clínico referido no acompanhamento individual” para compreender o sujeito a quem se acompanha enquanto uma pessoa que possui saberes e fazeres constituídos e constituintes de sua história e cultura (LOPES; BORBA; CAPELLARO, 2001, p. 235), as atividades propostas à sra. D. envolviam o seu território e os recursos nele existentes. Nesse sentido, as intervençôes ocorreram por meio de caminhadas pelo bairro de forma que a idosa explorasse a comunidade onde vivia (re)descobrindo novos grupos para acessar e expandir suas redes sociopessoais.

Para ampliar o leque de atividades potencializadoras e aprofundar as reflexóes sobre a problemática, a equipe SEAD buscou a equipe da Unidade Básica de Saúde (UBS) Santa Marta ${ }^{2}$ para novas parcerias. Além do atendimento psicológico, a UBS oferecia uma oficina para a terceira idade, conhecida como
Oficina Cuca Fresca. Nessa oficina os idosos realizavam atividades manuais e artesanais, estimulando não só a vida ativa e a qualidade de vida como a realização de atividades prazerosas e a sociabilidade a partir das novas amizades que eram construídas ao longo dos encontros.

Concomitante ao encaminhamento da idosa à UBS, as caminhadas com a sra. D. continuaram explorando novas vivências e incentivando o autocuidado com exercícios de alongamento e técnicas de respiração para que durante os momentos de irritabilidade, principalmente nas visitas dos enteados, a idosa conseguisse diminuir o nervosismo dando abertura a outras possibilidades de relacionamento com os filhos do marido. A equipe SEAD ainda incentivava a sra. D. a (re)encontrar atividades prazerosas não só na oficina da UBS, mas igualmente em seu cotidiano. Para que pudesse ter a oportunidade de vivenciar essa experiência lhe foi proposto que dividisse os cuidados ao marido, para além dos enteados e dos seus irmãos, com um cuidador contratado, já que tinha condiçôes financeiras para custeá-lo. Com a entrada desse profissional ela poderia tirar algum tempo para si e seus novos projetos.

Quanto ao fortalecimento das redes sociais de suporte da idosa, tendo em vista sua pertinência para a terapia ocupacional no campo social, pois essas redes irão auxiliar os sujeitos a sustentarem a complexidade de seus contextos (MALFITANO, 2005; BARROS; GHIRARDI; LOPES, 2002), no caso da sra. D. esse fortalecimento se deu a partir do acompanhamento familiar. A terapeuta ocupacional e a estagiária de terapia ocupacional ofereciam escuta, acolhimento e orientaçóes acerca dos novos arranjos cotidianos aos enteados e aos irmáos da Sra. D., envolvendo a família no processo de transformação daquela realidade.

Os filhos do sr. A. náo entendiam que a ajuda tinha que estar em consonância com a rotina da casa da sra. D., acreditavam que por serem filhos a ajuda poderia acontecer no momento que tivessem disponibilidade. Por meio de uma reuniáo familiar, compartilhada com os profissionais da UBS, a equipe SEAD trabalhou com a família extensa os conceitos de ajuda e cuidado, respaldando a sra. D. quanto aos cuidados que prestava e clarificando aos filhos do sr. A. a necessidade de assumirem alguns momentos de cuidado para que a idosa também pudesse ter tempo disponível para cuidar de si. Os profissionais da UBS pontuaram e explicaram as questôes de saúde do sr. A. aos filhos de modo a desmistificar as suspeitas de maus-tratos que tinham quanto à sra. D. 


\subsection{A sra. D., os rearranjos do cotidiano e a produção de novos significados no viver}

Os encontros e trocas ocorridos entre a sra. D. e a equipe SEAD produziram novos significados e sentidos na vida da idosa. As caminhadas lhe proporcionaram a valorização dos cuidados voltados para si, levando-a a refletir sua postura protetiva frente aos cuidados com o marido, (re)significando o sentimento de amor que construíram para além do cuidado do outro, mas para o cuidado de si para poder cuidar do outro. Essa mudança deu abertura para que os filhos tornassem a visitar o pai e se oferecerem para buscá-lo nos finais de semana, mesmo que esporadicamente. Ademais, o acompanhamento familiar proporcionou aos filhos um novo olhar frente às posturas da sra. D., que não revelavam os maus-tratos, mas sim o esgotamento de uma vida que perdera o sentido diante das rupturas.

O encaminhamento à UBS permitiu à sra. D. a atenção à sua saúde mental, a ajudou a construir uma nova rede pessoal e social de suporte e participação, e a assumir novos papéis, pois na Oficina Cuca Fresca foi convidada a ministrar algumas atividades que envolviam costura, bordado e pintura em tecido. $\mathrm{O}$ novo papel social lhe fez reacender o protagonismo da própria história e a fez se sentir parte de um coletivo, de modo a frequentar a UBS não só em busca de assistência à saúde, mas também para levar "quitutes" e panos de prato que fazia para doar aos profissionais, enxergando aquele espaço como um ponto de encontro, um local de trocas, em que podia exercer suas subjetividades e singularidades. As relaçôes construídas dentro da UBS transpassaram os muros do serviço e em pouco tempo a sra. D. ganhou novos amigos que começaram a frequentar sua casa, de maneira que suas atividades prazerosas (cozinhar, bordar, fazer exercícios de respiração) passaram a compor parte de sua rotina.

Os rearranjos do cotidiano da sra. D. e a produção de novos significados no seu viver aconteciam concomitantemente, num movimento de influência mútua e horizontal. Dessa forma, diante dos novos sentidos que vinha encontrando em sua vida, a idosa optou por contratar um cuidador para revezar os cuidados ao marido com ela e seu irmáo. Logo, nos meses que se seguiram às primeiras intervençôes, a sra. D. passou a se colocar com mais calma nos momentos de tensão, ganhou peso, dormia regularmente e mostrava-se mais feliz, afirmando à equipe SEAD que a partir do contato com esse serviço compreendeu quais eram os seus direitos $\mathrm{e}$ deveres, e que embora tivesse muitos deveres não se sentia mais desamparada em sua luta diária, pois, igualmente, sabia dos seus direitos.

\section{Considerações finais}

Retomar a memória social e conhecer a história de vida dos sujeitos são importantes no exercício de alteridade, possibilitando ao terapeuta ocupacional ver a vida do outro a partir do olhar desse outro e reconhecer-se também nesse outro. Assim, este profissional passa a sensibilizar-se tanto às demandas, quanto às necessidades e subjetividades do sujeito e/ou grupos que acompanha. O princípio de alteridade torna-se, pois, uma ferramenta que orienta e auxilia o terapeuta ocupacional a pensar em intervençóes e em açôes humanas, enquanto instrumento de mediação, que façam sentido e sejam significativas a quem se acompanha, contribuindo para o processo de produção de novos significados à vida e à ação protagonista dos sujeitos, considerando outras possibilidades de ser e estar existentes na cotidianidade.

Igualmente relevante é o recorte teórico-metodológico feito pelo terapeuta ocupacional frente às problemáticas encontradas levando em consideraçáo o campo de atuação. Nota-se que o Acompanhamento Individual e Territorial é uma metodologia potentes da terapia ocupacional social que permite o profissional utilizar um leque de intervenções capazes de auxiliá-lo, por meio do descentramento dos saberes técnicos em prol dos saberes construídos junto com os sujeitos, no fortalecimento e na prevenção das rupturas das redes de suporte relacionais e produtivas e no (re)rearranjo dessas mesmas redes quando o rompimento já está dado.

Ademais, ainda é importante reconhecer nessa experiência dois pilares que contribuíram para efetividade da atuação do terapeuta ocupacional: o trabalho em rede, com o compartilhamento das açóes com outros dispositivos, e o trabalho em equipe. Embora o artigo tenha se atentado às intervençôes propostas pela terapia ocupacional, estas se deram junto com o assistente social, no que diz respeito à equipe SEAD-Maruípe, e junto com a equipe multiprofissional da UBS Santa Marta (assistente social, psicólogo e enfermeiro). Ambos os alicerces sáo de uma riqueza tamanha, pois propiciaram a troca de saberes entre áreas de conhecimento distintas gerando novas reflexôes e construções inovadoras de intervenção, de forma que o sujeito acompanhado pudesse ser visto em sua multipluralidade num diálogo constante entre as tantas partes que cabem em si e no seu coletivo.

Compreende-se, pois, que lidar com a vida no plano real e no campo social exige um exercício contínuo ao terapeuta ocupacional de ir de frente 
às resolubilidades imediatistas incentivadas pelo modo de ser capitalista, buscando a coerência de suas práticas com os contextos nos quais elas irão se desenvolver. Como resultado desse exercício na experiência relatada, o acompanhamento do caso da sra. D continuou pela equipe SEAD, entretanto, não mais através de atendimentos domiciliares sistemáticos, mas por meio do monitoramento que consiste em um acompanhamento com visitas mais espaçadas e com contatos telefônicos, ações estas que compóem o processo de desligamento de caso nos serviços socioassistenciais. Nas visitas e nos telefonemas que se seguiram era notável: o diálogo já não estava mais como único meio de expressão para a sra. D., mas um entre tantos outros (re)descobertos.

\section{Agradecimentos}

Às demais integrantes da equipe SEAD: Gabriela Queiroz Vieira Neves (terapeuta ocupacional e preceptora do estágio de Terapia Ocupacional Social no CREAS-Maruípe) e Viviane Maria Pessoa (assistente social), que contribuíram, a partir das trocas e orientaçóes, para a vivência da experiência relatada. À sra. D., por sua disponibilidade e abertura em participar das intervençôes propostas pela equipe SEAD-Maruípe.

\section{Referências}

ALMEIDA, M. C. et al. Processos e práticas de formalização da Terapia Ocupacional na Assistência Social: alguns marcos e desafios. Cadernos de Terapia Ocupacional da UFSCar, São Carlos, v. 20, n. 1, p. 33-41, 2012.

BARROS, D. D.; GHIRARDI, M. I. G.; LOPES, R. E. Terapia Ocupacional Social. Revista de Terapia Ocupacional da Universidade de São Paulo, São Paulo, v. 13, n. 3, p. 95-103, 2002.

BARROS, D. D.; LOPES, R. E.; GALHEIGO, S. M. Terapia ocupacional social: concepçōes e perspectivas. In: CAVALCANTI, A.; GALVÃO, C. (Org.). Terapia ocupacional: fundamentaçáo e prática. Rio de Janeiro: Guanabara Koogan, 2007a. p. 347-353.

BARROS, D. D.; LOPES, R. E.; GALHEIGO, S. M. Novos espaços, novos sujeitos: a terapia ocupacional no trabalho territorial e comunitário. In: CAVALCANTI, A.; GALVÃO, C. (Org.). Terapia ocupacional: fundamentação e prática. Rio de Janeiro: Guanabara Koogan, 2007b. p. 354-363.

BRASIL. Ministério da Saúde. Violência Intrafamiliar: orientaçóes para a prática em serviço. Brasília, 2002. (Caderno de Atençâo Básica, 8).

BRASIL. Ministério do Desenvolvimento Social e Combate à Fome. Resoluçáo no 109, de 11 de novembro de 2009. Tipificaçáo Nacional de Serviços socioassistenciais. Diário
Oficial da República Federativa do Brasil, Poder Executivo, Brasília, DF, 25 nov. 2009. Seção 1.

BRASIL. Ministério do Desenvolvimento Social e Combate à Fome. Resoluçáo nº 17, de 20 de junho de 2011. Ratificar a equipe de referência definida pela Norma Operacional Básica de Recursos Humanos do Sistema Único de Assistência Social - NOB-RH/SUAS e Reconhecer as categorias profissionais de nível superior para atender as especificidades dos serviços socioassistenciais e das funçôes essenciais de gestão do Sistema Único de Assistência Social - SUAS. Diário Oficial da República Federativa do Brasil, Poder Executivo, Brasília, DF, 21 jun. 2011. Seção 1. Disponível em: <http://www.sedest.df.gov.br/ sites/300/382/00002355.pdf>. Acesso em: 16 de nov. 2014.

CASTEL, R. Da indigência à exclusão, à desfiliação- precariedade do trabalho e vulnerabilidade relacional. In: LANCETTI, A. Saúde loucura. São Paulo: HUCITEC, 1993. p. 21-48.

CONSELHO FEDERAL DE FISIOTERAPIA E TERAPIA OCUPACIONAL - COFFITO. Resolução no 383, de 22 de dezembro de 2010. Define as competências do Terapeuta Ocupacional nos Contextos Sociais e dá outras providências. Diário Oficial da República Federativa do Brasil, Poder Executivo, Brasília, DF, 25 dez. 2010a. Disponível em: <http://www.coffito.org.br/publicacoes/pub_view. asp?cod=1960\&psecao=9>. Acesso em: 16 nov. 2014.

CONSELHO MUNICIPAL DO IDOSO DE VITÓRIA - COMID. Viver e envelhecer: manual de orientação ao estudo sobre envelhecimento. Vitória, 2010b.

COSTA, S. L. Os sentidos da comunidade: construçōes intergeracionais de memória coletiva na Ilha das Caieiras, em Vitória/ES. 2008. 337 f. Tese (Doutorado em Psicossociologia de Comunidades e Ecologia Social)-Universidade Federal do Rio de Janeiro, Rio de Janeiro, 2008.

COSTA, S. L.; ALVARENGA, L.; ALVARENGA, A. M. Estudo de/com comunidades tradicionais: cultura, imagem e história oral. Revista Documenta Virtual, Rio de Janeiro, n. 17, p. 1-6, 2007. Disponível em: <http:// www.psicologia.ufrj.br/pos_eicos/pos_eicos/arqanexos/ documenta/documenta17indice.htm $>$. Acesso em: 16 nov. 2014.

GALHEIGO, S. M. O cotidiano na terapia ocupacional: cultura, subjetividade e contexto histórico-social. Revista de Terapia Ocupacional da Universidade de São Paulo, São Paulo, v. 14, n. 3, p. 104-109, 2003.

LOPES, R. E. et al. Oficinas de atividades com jovens da escola pública: tecnologias sociais entre educação e terapia ocupacional. Revista Interface Comunicaçāo, Saúde, Educação, Botucatu, v. 15, n. 3, p. 277-288, 2011.

LOPES, R. E.; BORBA, P. L. O.; CAPELLARO, M. Acompanhamento individual e articulação de recursos em Terapia Ocupacional Social: compartilhando uma experiência. O Mundo da Saúde, São Paulo, v. 35, n. 2, p. 23338, 2011.

MALFITANO, A. P. S. Campos e núcleos de intervenção. Revista de Terapia Ocupacional da Universidade de São Paulo, São Paulo, v. 16, n. 1, p. 1-8, 2005. 


\section{Contribuição dos Autores}

Ambas as autoras foram responsáveis pela reflexão, análise e redação das ideias desenvolvidas no artigo.

\section{Notas}

${ }^{1}$ Estar junto com o outro na Terapia Ocupacional Social significa acompanhar, estar ao lado, priorizar os desejos e vontades dos sujeitos.

${ }^{2}$ Unidade de saúde referência para a sra. D. quanto aos serviços de saúde, também localizada no bairro Maruípe, Vitória, ES. 